\title{
Unreported deaths in pediatric surgery and anesthesia: a national, twenty year report
}

\author{
ALESSANDRO PUTZU ${ }^{1}$, EDOARDO CALDERINI ${ }^{2}$, VALENTINA CAMARDA ${ }^{1}$, GIOVANNI LANDONI ${ }^{1}$ \\ ${ }^{1}$ Department of Anesthesia and Intensive Care, IRCCS San Raffaele Scientific Institute, Milan, Italy \\ ${ }^{2}$ Department of Anesthesia, Intensive Care, and Emergency, Fondazione IRCCS Ca' Granda, Ospedale Maggiore Policlinico, Milan, Italy
}

Corresponding author:

Giovanni Landoni

Department of Cardiothoracic Anesthesia and Intensive Care

Ospedale San Raffaele

Via Olgettina 60, Milano, 20132 Italy

Phone: +39-02-26436154

Fax +39-02-26437178

E-mail: landoni.giovanni@hsr.it

\section{ABSTRACT}

Introduction. Pediatric perioperative mortality is extremely low but it is underreported in peer-reviewed journals, making it difficult to understand the magnitude of the problem. The aim of this study was to identify pediatric deaths reported by the mass media over a 20 - year period in pediatric and non-pediatric hospitals.

Materials and methods. The international search engines Google, Yahoo, Bing, and the online archives of major newspapers were searched independently by 3 trained investigators (1st January 1995 to 1st January 2015) looking for children ( $<18$ years old) who died in the perioperative period in Italy, excluding obstetrical or neonatal deaths.

Results. A total of 51 fatal events were identified with 41 cases ( $80 \%$ ) being elective procedures. Most fatal events (31 cases, $61 \%)$ occurred in non-specialized hospitals, 12 cases $(23 \%)$ occurred in high-volume non-pediatric hospitals, and 8 cases (16\%) in pediatric hospitals. The most frequently represented operations were head/ neck 21 cases (41\%), abdominal 11 cases (21\%), and orthopedic surgery 9 cases (18\%). The reported causes of death were equally distributed between surgical (25 cases, 49\%) and anesthesiological complications. The most common causes of death were hemorrhage $(n=11)$, difficult airway management $(n=10)$, infections $(n=6)$, and allergic reactions $(n=4)$. In $25 \%$ of cases (13 cases), the complication resulted in intraoperative death.
Conclusion. Our findings suggest that most pediatric deaths reported by mass media occurred in non-pediatric centers during elective surgical procedures (e.g. adenotonsillectomy and appendicectomy), suggesting that referral to large-volume or pediatric hospitals should be preferred. Moreover, one of the most commonly reported complications was difficult airway management, confirming that this aspect should have a central role in physician training and practice.

\section{INTRODUCTION}

Millions of children undergo surgical procedures every year. Only in the USA, every year more than half a million pediatric surgical operations are performed. $(1,2)$ Most of these surgical procedures are elective and uneventful procedures (e.g. appendectomy, tonsillectomy, bone fracture fixation). $(3,4)$

Commonly, children have few comorbidities and a good functional reserve. However, perioperative pediatric patients, due to their anatomical and physiological characteristics, have to be handled differently from adult patients, requiring a high level of pediatric expertise from each member of the medical and paramedical team. This has lead to the creation of pediatric hospitals, where surgeons and anesthesiologists, as well as internists and nursing staff, have received proper, specific education in pediatric medicine. Unfortunately, children perioperative mortality still occurs.
A large, European, observational study found an average $4 \%$ mortality among adult patients undergoing non-cardiac surgery in Europe, with mortality rates varying widely between countries (from $1.2 \%$ to $21.5 \%)$, (4) suggesting that there are modifiable factors affecting mortality. A large multicenter observational study on pediatric perioperative mortality is still lacking. National reports recording mortality rates in surgical pediatric sub-settings confirm that there is no surgical procedure without risks and that some sub-specialty (e.g. cardiac surgery, transplants) procedures are at particularly elevated risk. (3)

Few case reports or case series of pediatric perioperative mortality reach the publication level in peer-reviewed journals, making it hard to understand the impact of the problem. On the other side, reports of these unfortunate events have a massive media resonance due to the susceptibility of the general population to the topic, particularly when fatal complications occur during an elective or low-risk procedure in otherwise healthy children.

The aim of this study was to identify all the perioperative pediatric deaths reported by the mass media in recent years in Italy and to report the occurrence in pediatric and non-pediatric specialized hospitals.

\section{MATERIALS AND METHODS}

\section{Search Strategy}

The international search engines Google, Yahoo, Bing and the online archives of 
major national newspapers (Corriere della Sera, la Repubblica, la Stampa, il Messaggero) were searched independently by 3 trained investigators to identify pediatric perioperative deaths. Divergences were resolved by consensus.

We limited our search to a 20-year period (1st January 1995 to 1st January 2015). The search strategies are reported in detail in the Supplemental Material and included keywords like "surgery", "anesthesia", "death", "child", "children", and respective synonyms (Supplemental Material 1).

\section{Study Selection}

References obtained from searches were first independently examined by 3 investigators and then, if potentially relevant, collected as complete articles. Possible report overlaps were checked and duplicates excluded from the analysis.

Inclusion criteria were: age $<18$ years; perioperative deaths; reports from Italian hospitals. Exclusion criteria were: complications not followed by death; reports before 1995; obstetrical or neonatal deaths; non-surgical related deaths (e.g. central venous catheter positioning in non-surgical patient); major trauma; palliative surgery in end stage diseases.

\section{Data Abstraction and Study Character- istics}

Three trained investigators abstracted baseline, procedural, and outcome data using a data-recording form developed for this purpose. The following data were abstracted: patient's age, sex, date of the surgical operation, region and city, type of hospital, elective or unplanned surgery, surgical diagnosis and procedure, type of anesthesia, type of complication and its relation to anesthesia, time between procedure and death, and web link to the article.

Italy has approximately 60 million inhabitants including about 9 million children younger than 18 years of age, a number that is slightly decreasing over the years because of a declining birth rate. In Italy there are 13 pediatric hospitals (5) and approximately 50 high volume hospitals handling several pediatric cases every day. All the other hospitals are considered as nonpediatric.

The primary endpoint of the present review was to identify all mortality events that occurred in the 20 -year study period and to identify how many deaths occurred in non-specialized hospitals.

Data are presented as numbers and percentages.

\section{RESULTS}

A total of 51 perioperative deaths were identified. Major exclusions were represented by non-fatal major complications (3 cases), reports before 1995 (4 cases), non-surgical related deaths (3 cases), and obstetrical or neonatal deaths (7 cases).

The age ranged from 1 month to 17 years: 9 cases $(18 \%)$ were younger than 3 years of age and 35 cases $(69 \%)$ were male (table 1 ). The majority of the surgical procedures were elective (41 cases, $80 \%$ ).

The most represented operations were head/neck surgery ( 21 cases, $41 \%$, with 15 adenotonsillectomy), abdominal surgery (9 cases, 18\%, with 4 appendectomy), and orthopedic surgery (9 cases, 18\%, with 5 bone fracture fixation). Notably, only 7 cases $(14 \%)$ were cardiac surgery procedures (figure 1).

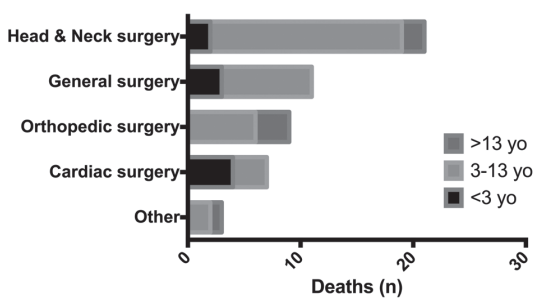

Figure 1. Pediatric perioperative deaths by surgical specialty.

Values within each surgical specialty represent the number of deaths, stratified by age. The largest number of deaths occurred in head/neck surgery.

Anesthesiological cause of death accounted for $42 \%$ of all cases ( 22 cases). The most frequently reported events were difficult airway management $(n=10)$ and allergic reactions $(n=4)$ (figure 2). Notably all but two cases occurred in patients with planned general anesthesia.

Surgical or non-anesthesiological causes of death ( 25 cases, $49 \%$ ) were mainly represented by postoperative hemorrhage $(\mathrm{n}=11)$, postoperative complications (e.g. acute respiratory failure $)(\mathrm{n}=7)$, and infection $(n=6)$ (figure 2).

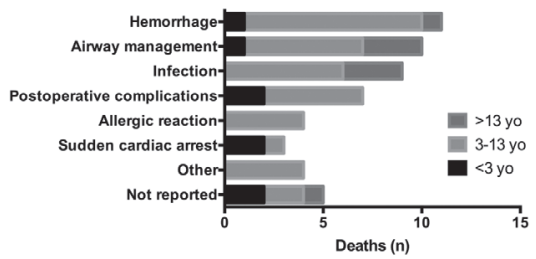

Figure 2. Pediatric perioperative deaths by cause of death.

Values within each complication group represent the number of deaths, stratified by age.

In $25 \%$ of cases (13 cases), the complication led to an intraoperative death, mainly because of anesthesiological complications (9 of 13 cases). Only 2 children (4\%) died more than 3 months after surgery.

Seventeen cases (33\%) occurred in hospitals located in Northern Italy, a region that accounts for $46 \%$ of the Italian population (0.030 fatal events per million inhabitants per year), 13 cases (26\%) in central Italy $(20 \%$ of the Italian population, with 0.054 fatal events per million inhabitants per year), and 21 cases (41\%) in southern Italy $(34 \%$ of the Italian population, with 0.051 fatal events per million inhabitants per year).

There was no significant trend towards an increase or decrease of the number of reported deaths per year during the study period (Supplemental material 2). When considering the date and location of death, we found only one cluster in 2005, with 3 events occurring in the same month and in the same region.

Even if most pediatric operations are most likely performed in pediatric or high-volume hospitals, (5) only a few deaths occurred in these centers (table 1). In fact, $61 \%$ of the cases occurred in non-specialized hospitals, with causes equally distributed between surgical and anesthesiological. This percentage was about the same (63\%) when limiting the analysis to 35 children undergoing elective non-cardiac surgery (table 1). 
Table 1. Characteristics of Pediatric Perioperative Deaths (51 cases).

\begin{tabular}{|c|c|c|}
\hline Characteristics & $\begin{array}{l}\text { Deaths, n } \\
(\%)\end{array}$ & $\begin{array}{l}\text { The most important finding in this manu- } \\
\text { script is that unexpected perioperative }\end{array}$ \\
\hline \multicolumn{2}{|l|}{ Age category } & \multirow{5}{*}{$\begin{array}{l}\text { dia reporting, less than } 3 \text { cases per year in } \\
\text { a country with approximately } 9 \text { million } \\
\text { children and over } 250,000 \text { pediatric surgi- } \\
\text { cal procedures per year. (5) Nonetheless, } \\
\text { our findings suggest that this figure could } \\
\text { be further reduced since: a) most unex- }\end{array}$} \\
\hline$<3$ years old & $9(18 \%)$ & \\
\hline 3-13 years old & $36(70 \%)$ & \\
\hline$>13$ years old & $6(12 \%)$ & \\
\hline \multicolumn{2}{|l|}{ Sex } & \\
\hline Female & $16(31 \%)$ & \multirow{9}{*}{$\begin{array}{l}\text { pected deaths occurred in elective sur- } \\
\text { gery children operated in non-specialized } \\
\text { hospitals (these patients could have been } \\
\text { theoretically referred to high-volume or } \\
\text { to pediatric hospitals); and b) difficult air- } \\
\text { way management was the most common } \\
\text { anesthesiological complication and it is } \\
\text { often related to lack of specific pediatric } \\
\text { expertise. These findings are important } \\
\text { for planning future health policies and to } \\
\text { guide physicians and parents in the refer- } \\
\text { ral process. }\end{array}$} \\
\hline Male & $35(69 \%)$ & \\
\hline \multicolumn{2}{|c|}{ Elective vs. urgent surgery } & \\
\hline Urgent surgery & $10(20 \%)$ & \\
\hline Elective surgery & $41(80 \%)$ & \\
\hline \multicolumn{2}{|c|}{ Location of the Hospital } & \\
\hline Northern Italy & $17(33 \%)$ & \\
\hline Central Italy & $13(26 \%)$ & \\
\hline Southern Italy & $21(41 \%)$ & \\
\hline
\end{tabular}

Type of Hospital

Non-specialized hospital $31(61 \%)$

High-volume non-pediatric $12(23 \%)$

hospital

Pediatric hospital $8(16 \%)$

Type of Hospital (excluding

cardiac surgery and urgent

surgery)

\begin{tabular}{ll}
\hline Non-specialized hospital & $22(63 \%)$ \\
\hline $\begin{array}{l}\text { High-volume non-pediatric } \\
\text { hospital }\end{array}$ & $7(20 \%)$ \\
\hline $\begin{array}{l}\text { Pediatric hospital } \\
\text { Cause of death }\end{array}$ & $6(17 \%)$ \\
\hline Hemorrhage & $11(21 \%)$ \\
\hline Difficult airway management & $10(20 \%)$ \\
\hline Postoperative complications & $7(14 \%)$ \\
\hline Infections & $6(12 \%)$ \\
\hline Allergic reactions & $4(8 \%)$ \\
\hline Sudden cardiac arrest & $3(6 \%)$ \\
\hline Spinal anesthesia complications $1(2 \%)$ \\
\hline $\begin{array}{l}\text { Epidural anesthesia complica- } \\
\text { tions }\end{array}$ & $1(2 \%)$ \\
\hline Postoperative stroke & $1(2 \%)$ \\
\hline Intraoperative airway lesion & $1(2 \%)$ \\
\hline Malignant hyperthermia & $1(2 \%)$ \\
\hline Not reported & $5(9 \%)$ \\
\hline Timing of death & $13(25 \%)$ \\
\hline Intraoperative & $36(71 \%)$ \\
\hline Postoperative $<3$ months & $2(4 \%)$ \\
\hline Postoperative $>3$ months & \\
\hline
\end{tabular}

\section{DISCUSSION}

The most important finding in this manuscript is that unexpected perioperative death rate is rare: according to mass media reporting, less than 3 cases per year in a country with approximately 9 million cal procedures per year. (5) Nonetheless, our findings suggest that this figure could be further reduced since: a) most unexvergery children operated in non-specialized theoretically referred to high-volume or to pediatric hospitals); and b) difficult airway management was the most common anesthesiological complication and it is expertise. These findings are important ral process

The use of media reports as a source of medical fatalities and outcomes is well established. (6-9) However, it must be addressed that the results could be biased by possible selective reporting from national mass media. It is possible that our results represent only a part of the total amount of perioperative pediatric fatalities and that we were not able to calculate the real incidence of this event among children. Obviously, the likelihood of a death report reaching the media is strictly related to the expected or perceived risk of death (the lower the risk, the higher the likelihood that the case will be reported by mass media). In fact, most surgical procedures were represented by low-risk surgery (e.g. adenotonsillectomy and appendectomy) and only 7 children underwent cardiac surgery (which is perceived as high-risk surgery and where the relatives are properly informed of mortality rates).

The fact that all but two cases occurred under general anesthesia suggests the need for careful assessment of the indication for locoregional anesthesia in every case, especially in children. This should also take into consideration the recent issue of altered neurobehavioral outcomes after general anesthesia in children. $(10,11)$ However, the management of locoregional anesthesia in pediatric patients is generally technically difficult, impossible in some surgical subspecialties, and the real outcome of general vs. locoregional anesthesia should be assessed with multicenter randomized trials.

As highlighted by our findings, difficult airway management in children had a central role in several fatal events. The importance of specific training in pediatric anesthesia is essential and an appropriate approach to difficult pediatric airways is crucial. $(12,13)$

Our findings cannot be compared to other published studies, since this was the first time that an attempt was performed to estimate unexpected and unreported perioperative mortality through mass media report. We included all kinds of complications, both surgical and anesthesiological while other reviews and databases selectively report anesthesiological or surgical complications, $(1,3,14,15)$ not allowing an understanding of the real overall mortality rate in the pediatric surgical setting.

A report of over two million children that underwent surgical procedures, provided data relating to inpatient pediatric surgical outcomes in U.S.A hospitals, and showed an overall mortality of $0.85 \%$. (3) Among elective procedures, cardiac, vascular, and transplant surgery showed the highest mortality. Our results include mostly low risk procedures, such as head and neck surgery (stated by the USA report as having $0.03 \%$ mortality rate), probably due to the higher probability of reporting by the media in case of unexpected fatalities during these low morbidity procedures.

Among anesthesiological complications, a systematic review of the literature investigating the period 2001-2011 showed that in developed countries perioperative mortality rates range from 0.41 to 13.4 per 10,000 anesthetics. (14) A recent meta-analysis of acute severe complications of pediatric anesthesia failed to find any strong data regarding mortality, underlying the fact that the majority of the studies analyzed failed to provide data. (15)

Children are often scheduled together with adults on operating lists in non-pediatric hospitals, but several studies suggested that in pediatric surgery, outcomes could be associated with hospitals' operative volumes or the surgeon's experience. (16) Furthermore, this mixed scheduling also leads to dilution of clinical skills for the staff involved, including surgeons and anesthe- 
siologists. A retrospective survey found that occasional pediatric anesthetic practice $(<100$ per year per anesthesiologist) carries up to a five times increased risk for complications when compared with anesthesiologists with $>200$ pediatric anesthesia procedures per year. (17) A recent meta-analysis found that children who were managed by specialized pediatric surgery teams had lower rates of negative appendectomy although mean length of stay was longer and there were no differences in clinical outcomes and complications. (18) A large multicenter randomized trial should explore systematically the outcome of pediatric vs. non-pediatric hospitals or low vs. high volume hospitals.

\section{STRENGTHS AND LIMITATIONS OF THE STUDY}

We limited our search to patients who died. These reports probably represent only a small part of the serious complications happening in the perioperative period. Nonetheless, we decided to focus on mortality because this is the most clinically relevant endpoint and the one which likely reaches the media level. We might have missed some unexpected events due to media under-reporting, even if it should be acknowledged that the unexpected death of a child reaches the media level most of the times. An Italian open-access nationalbased institutional registry is missing, so we were not able to compare the real incidence of perioperative mortality with the mass media reported incidence. The reports did not follow a cluster pattern and they were quite regular over time. This was an unexpected finding, since it was reasonable to hypothesize that the media were more likely to publish a child death if there was another event a few days or weeks before. Mass media articles did not clearly report the perioperative conditions (e.g. American Society of Anesthesiologists Classification, expertise level of the staff who provided care), not allowing for stratification of the results. Finally, the most important limitation of our analysis is that we did not crosscheck the validity of the media reports.

In conclusion, we identified 51 unexpected perioperative pediatric deaths occurring over a 20-year period in a country with approximately 9 million children aged less than 18 years of age. Even if this number is low, systematic national database reports should assess the real incidence of perioperative mortality since randomized trials should evaluate if this number could be reduced by referral of elective pediatric patients to pediatric or high-volume hospitals and by improving specific technical skills.

\section{REFERENCES}

1. Tzong KYS, Han S, Roh A, Ing C. Epidemiology of pediatric surgical admissions in US children: data from the HCUP kids inpatient database. J Neurosurg Anesthesiol 2012;24:391-5. doi:10.1097/ANA.0b013e31826a0345.

2. Sømme S, Bronsert M, Morrato E, Ziegler M. Frequency and variety of inpatient pediatric surgical procedures in the United States. Pediatrics 2013;132:e1466-72. doi:10.1542/peds.2013-1243.

3. Abdullah F, Gabre-Kidan A, Zhang Y, Sharpe L, Chang DC. Report of 2,087,915 surgical admissions in U.S. children: inpatient mortality rates by procedure and specialty. World J Surg 2009;33:2714-21. doi:10.1007/s00268-009-0219-8.

4. Pearse RM, Moreno RP, Bauer P, Pelosi P, Metnitz P, Spies C, et al. Mortality after surgery in Europe: a 7 day cohort study. Lancet (London, England) 2012;380:1059-65. doi:10.1016/S0140-6736(12)61148-9.

5. Italian Ministry of Health. Le caratteristiche dell'ospedalizzazione pediatrica in Italia (dal neonato all'adolescente). Ital Natl Inst Stat (Website) 2005. (accessed November 23, 2015). Available from: http://www.salute.gov.it/portale/documentazione/p6_2_2_1. jsp?lingua $=$ italiano\&id $=999$.

6. Head R, Murray J, Sarrassat S, Snell W, Meda N, Ouedraogo M, et al. Can mass media interventions reduce child mortality? Lancet 2015;386:97-100. doi:10.1016/S0140-6736(14)61649-4.

7. Yoo B-K, Holland ML, Bhattacharya J, Phelps CE, Szilagyi PG. Effects of mass media coverage on timing and annual receipt of influenza vaccination among Medicare elderly. Health Serv Res 2010;45:1287-309. doi:10.1111/j.1475-6773.2010.01127.x.

8. Lee HH, Milgrom P, Starks H, Burke W. Trends in death associated with pediatric dental sedation and general anesthesia. Paediatr Anaesth 2013;23:741-6. doi:10.1111/pan.12210.

9. Holtzman NA, Bernhardt BA, Mountcastle-Shah E, Rodgers JE, Tambor E, Geller G. The quality of media reports on discoveries related to human genetic diseases. Community Genet 2005;8:133-44. doi:10.1159/000086756.

10. DiMaggio C, Sun LS, Ing C, Li G. Pediatric anesthesia and neurodevelopmental impairments: a Bayesian meta-analysis. J Neurosurg Anesthesiol 2012;24:376-81. doi:10.1097/ANA.0b013e31826a038d.

11. Wang X, Xu Z, Miao C-H. Current clinical evidence on the effect of general anesthesia on neurodevelopment in children: an updated systematic review with meta-regression. PLoS One 2014;9:e85760. doi:10.1371/journal.pone.0085760.

12. Sheeran PW, Walsh BK, Finley AM, Martin AK, Brenski AC. Management of difficult airway patients and the use of a difficult airway registry at a tertiary care pediatric hospital. Paediatr Anaesth 2014;24:819-24. doi:10.1111/pan.12356.

13. Calder A, Hegarty M, Davies K, von Ungern-Sternberg BS. The difficult airway trolley in pediatric anesthesia: an international survey of experience and training. Paediatr Anaesth 2012;22:1150-4. doi:10.1111/pan.12058.

14. Gonzalez LP, Pignaton W, Kusano PS, Módolo NSP, Braz JRC, Braz LG. Anesthesia-related mortality in pediatric patients: a systematic review. Clinics (Sao Paulo) 2012;67:381-7.

15. Mir Ghassemi A, Neira V, Ufholz L-A, Barrowman N, Mulla J, Bradbury CL, et al. A systematic review and meta-analysis of acute severe complications of pediatric anesthesia. Paediatr Anaesth 2015;25:1093-102. doi:10.1111/pan.12751.

16. Evans C, van Woerden HC. The effect of surgical training and hospital characteristics on patient outcomes after pediatric surgery: a systematic review. J Pediatr Surg 2011;46:2119-27. doi:10.1016/j.jpedsurg.2011.06.033. 
17. Auroy Y, Ecoffey C, Messiah A, Rouvier B. Relationship between complications of pediatric anesthesia and volume of pediatric anesthetics. Anesth Analg 1997;84:234-5.

18. Healy DA, Doyle D, Moynagh E, Maguire M, Ahmed I, Ahmed AS, et al. Systematic Review and Meta-Analysis on the Influence of Surgeon Specialization on Outcomes Following Appendicectomy in Children. Medicine (Baltimore) 2015;94:e1352. doi:10.1097/ MD.0000000000001352.

\section{SUPPLEMENTAL MATERIAL 1}

Search strategy

The international search engines Google, Yahoo, Bing, and the online archives of major newspapers were searched independently by 3 trained investigators (1st January 1995 to 1 st January 2015) including children ( $<18$ years $)$ who died in the perioperative period in Italy, excluding obstetrical or neonatal deaths. The search strategy included simple search strings. All the most common synonyms for each word were tested.

Bambino morto chirurgia Bambina morta chirurgia Bimbo morto chirurgia Bimba morta chirurgia Ragazzo morto chirurgia Ragazza morta chirurgia Neonato morto chirurgia Bambino morto operazione Bambina morta operazione Bimbo morto operazione Bimba morta operazione Ragazzo morto operazione Ragazza morta operazione Neonato morto operazione
Bambino morto anestesia Bambina morta anestesia Bimbo morto anestesia Bimba morta anestesia Ragazzo morto anestesia Ragazza morta anestesia Neonato morto anestesia Bambino morte chirurgia Bambina morte chirurgia Bimbo morte chirurgia Bimba morte chirurgia Ragazzo morte chirurgia Ragazza morte chirurgia Neonato morte chirurgia Bambino morte operazione Bambina morte operazione Bimbo morte operazione Bimba morte operazione Ragazzo morte operazione Ragazza morte operazione Neonato morte operazione Bambino morto anestesia Bambina morta anestesia Bimbo morto anestesia Bimba morta anestesia Ragazzo morto anestesia Ragazza morta anestesia Neonato morto anestesia

\section{SUPPLEMENTAL MATERIAL 2}

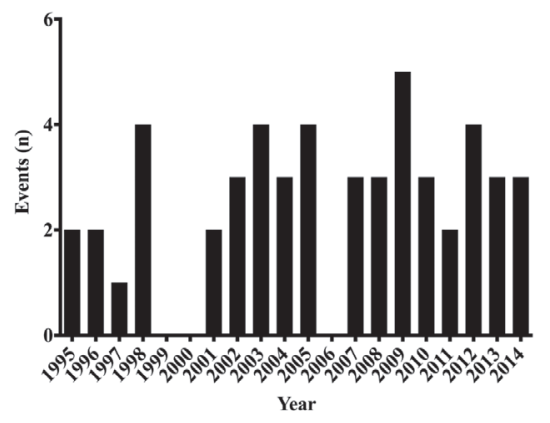

Fatal events per year through the 20-year period 